\title{
Risk of non-melanoma skin cancer with biological therapy in common inflammatory diseases: a systemic review and meta-analysis
}

\author{
Ruolin Liu', Qianyi Wan², Rui Zhao ${ }^{2}$, Haitao Xiao ${ }^{1}$, Ying $\mathrm{Cen}^{1^{*}}{ }^{10}$ and Xuewen $\mathrm{Xu}^{1^{*}}$
}

\begin{abstract}
Background: Most previous studies compared the risk for non-melanoma skin cancer (NMSC) in biologic-treated common inflammatory diseases with the general population. Whether the increased NMSC risk is caused by the disease itself, the biologics, or both remains unknown.

Methods: We systematically searched PubMed, Embase, Medline, Web of Science, and Cochrane Library from inception to May 2021. Studies were included if they assessed the risk of NMSC for rheumatoid arthritis (RA), inflammatory bowel disease (IBD), or psoriasis patients treated with biologics compared with patients not receiving biologics. Pooled relative risks (RRs) and 95\% confidence intervals (Cls) were calculated using the fixed- or random-effects model.

Results: The current meta-analysis included 12 studies. Compared with patients with the inflammatory disease without biologics, patients receiving biological therapy were associated with an increased risk for NMSC (RR 1.25, 95\% Cl 1.14 to 1.37 ), especially in patients with RA (RR $1.24,95 \% \mathrm{Cl} 1.13$ to 1.36 ) and psoriasis (RR $1.28,95 \% \mathrm{Cl} 1.07$ to 1.52 ), but not in patients with IBD (RR 1.49, 95\% Cl 0.46 to 4.91). The risks for squamous cell skin cancer and basal cell skin cancer were both increased for patients receiving biologics. However, the risk of NMSC did not increase in patients treated with biologics less than 2 years.
\end{abstract}

Conclusions: Current evidence suggests that increased risk of NMSC was identified in RA and psoriasis treated with biologics compared with patients not receiving biologics, but not in patients with IBD. The inner cause for the increased risk of NMSC in IBD patients should be further discussed.

Keywords: Non-melanoma skin cancer, Inflammatory bowel disease, Psoriasis, Rheumatoid arthritis, Biologics

\section{Background}

Rheumatoid arthritis (RA), inflammatory bowel disease (IBD), and psoriasis are three common immune-mediated inflammatory diseases involved with epithelial or

\footnotetext{
*Correspondence: scdx2019324020078@stu.scu.edu.cn; xuxuewen@scu.edu. cn

${ }^{1}$ Department of Burn and Plastic Surgery, West China Hospital of Sichuan University, No 37 Wainan Guoxue Road, Chengdu 610041, China Full list of author information is available at the end of the article
}

connective tissue with overlapping genetic susceptibility and relatively high incidence [1-4]. Previous studies found that all these three diseases increased cancer incidence in epithelial or connective tissue, including melanoma and non-melanoma skin cancer (NMSC) [5-10]. It is worth noting that these three diseases also have overlapping treatment modalities, and they are characterized by long-term treatment [4]. Biologics, including tumor necrosis factor inhibitors (TNFIs; adalimumab, original author(s) and the source, provide a link to the Creative Commons licence, and indicate if changes were made. The images or other third party material in this article are included in the article's Creative Commons licence, unless indicated otherwise in a credit line to the material. If material is not included in the article's Creative Commons licence and your intended use is not permitted by statutory regulation or exceeds the permitted use, you will need to obtain permission directly from the copyright holder. To view a copy of this licence, visit http://creativecommons.org/licenses/by/4.0/. The Creative Commons Public Domain Dedication waiver (http://creativeco mmons.org/publicdomain/zero/1.0/) applies to the data made available in this article, unless otherwise stated in a credit line to the data. 
etanercept, infliximab), CD20 inhibitor (rituximab), antagonists of the IL-17 pathway (ustekinumab, secukinumab, and ixekizumab), and antagonists of the IL-6 pathway (tocilizumab) were licensed for the treatment of RA, IBD, or psoriasis in the early part of the last decade [11-14]. Although these drugs are widely used and their efficacy is well-proven, their role in the risk of developing a variety of cancers remains unclear [15]. The above results raise a question, namely, whether the diseases increased the risk for NMSC, or the use of biological agents increased this risk, or both.

Esse et al. identified no significant association between the risk of melanoma and biological treatment for patients with common inflammatory diseases compared with those receiving non-biological therapy, which showed that biological therapy is not critical in developing melanoma for patients with inflammatory diseases [16]. Van Lümig et al. found that patients with psoriasis had a 5.5 (95\% confidence interval [CI], 2.2 to 13.4) higher rate of NMSC compared with patients with RA with correction for the duration of TNFIs and other systemic therapies [17]. Therefore, the impact of biological therapy on these three diseases for the occurrence of NMSC should be further investigated to determine the inner relationship between the increasing incidence of NMSC and biologically treated inflammatory diseases.

Previous studies in biologic-treated IBD and psoriasis have found an elevated incidence of NMSC in pan-cancer research [18-20], while these studies selected the general population as a comparison, which cannot distinguish whether the increased risk of NMSC comes from diseases or biological agents. At present, a meta-analysis evaluating the risk of NMSC in biologic-treated patients versus non-biologic-treated patients has been confined to RA patients [21,22]. A systemic review identified that TNFIs therapy is associated with increased risk of NMSC versus non-TNFIs therapy (relative risk [RR], 1.28; 95\% CI 1.19 to 1.38) [22]; other kinds of biologics were not included in the analysis [23]. The risk of NMSC in individuals with IBD or psoriasis treated with biological treatment versus those not receiving biological therapy is even less apparent. A systemic review on the occurrence of any cancer associated with the use of TNFIs for IBD therapy included the studies about NMSC compared with the general population, and no effect size calculation was performed [19, 24]. To the best of our knowledge, the only meta-analysis of any malignancy amongst biologic-treated psoriasis patients examined the risk of NMSC also compared with the general population [18].

To address the above issues, we performed a systematic review evaluating the risk of NMSC in patients with common inflammatory diseases treated with biologics. Considering the inherent relevance of the three diseases, connective studies are necessary to clarify whether the source of the increased risk of NMSC is related to biological agents, the diseases, or both. We aimed to present a therapeutically meaningful review of the available information to help clinicians make better therapy decisions.

\section{Methods}

\section{Data sources and searches}

The following terms were used to search PubMed, Embase, Medline, Web of Science, and Cochrane Library from their creation to May 2021 for eligible studies, with no language constraints: "arthritis rheumatoid" or "rheumatoid arthritis" or "rheumatoid chronic arthritis" or "inflammatory bowel disease" or "crohn" or "psoriasis" or "inflammatory disease" or "immune-mediated disease"," "skin cancer" or "skin neoplasm" or "NMSC", and "TNFI" or "tumor necrosis factor inhibitor" or "tumor necrosis factor- $\alpha$ antagonist"* or "TNF- $\alpha$ inhibitor" or "anti-TNF" or "biologic" or "infliximab" or "adalimumab" or "etanercept" or "golimumab" or "certolizumab" or "ustekinumab" or "rituximab" or "abatacept" or "tocilizumab" or "natalizumab" or "vedolizumab." The details of the search strategy are shown in Additional file 3: Supplementary search strategy. We also conducted a hand search from the reference lists of retrieved articles. This systematic review was conducted following the Preferred Reporting Items for Systematic Reviews and Meta-Analyses guidelines (PRISMA) and Meta-analysis of observational studies in Epidemiology guidelines (MOOSE) [23, 25-29]. The protocol for this meta-analysis was registered in the INPLASY database under the number INPLASY202170005.

\section{Study selection}

Randomized clinical trials, cohort studies, and nested case-control studies to investigate the risk of NMSC in patients with RA, IBD or psoriasis were included for further analysis. Studies were deemed potentially eligible if they matched the preset criteria listed below: (1) Studies on people with RA, IBD, or psoriasis; (2) treatment based on biologics; and (3) the risk estimates and 95\% CI of NMSC connected with biologics compared with those not receiving biologics. Studies were excluded if they met the following criteria: (1) use of the general population as the comparator; (2) non-clinical studies, such as animal studies; and (3) no relative risk could be extracted. Two researchers independently assessed study eligibility by screening study titles and abstracts and then reading the studies in total. Discrepancies about eligibility were settled by consensus with the third investigator. 


\section{Data extraction and assessment of the methodological quality}

Data extraction was performed independently by two reviewers. The following information was extracted from each paper: lead author; publication year; where the study was conducted; data source; study design; types of biological therapy; comparator therapy; treatment duration; disease severity indicators; sample size; effect size data and associated 95\% CI; and adjustment variables. The Newcastle-Ottawa Quality Assessment Scale (NOS) was used to evaluate study selection, matching, and outcome of the included studies [30-32].

\section{Statistical analysis}

The relative risk reported in included articles were chosen for inclusion in the meta-analysis. We calculated summary RRs and associated 95\% CIs for all outcomes using random- or fixed-effects models [33]. In studies that provided multiple RR estimates, the ones that were corrected for the highest number of confounders were used. We used the $\mathrm{Q}$ test to assess heterogeneity in outcomes across studies, and $\mathrm{I}^{2}$ statistic was used to quantify it. An $\mathrm{I}^{2}$ score of $50 \%$ or higher was considered to show significant heterogeneity. In anticipation of clinical heterogeneity, the random-effects model was performed. Begg's and Egger's tests were used to investigate publication bias. Subgroup analyses were conducted based on types of NMSC, types of biological therapy, study quality, treatment years, and sample size. All statistical analyses were conducted using Stata statistical software, version 15.1 (StataCorp., College Station, TX, USA).

\section{Results}

Search results

The process of article selection is shown in Fig. 1. The search strategy identified 7542 records from the databases. After removing 3011 duplicates, 4531 records were identified. We excluded 4447 entries by title and abstract

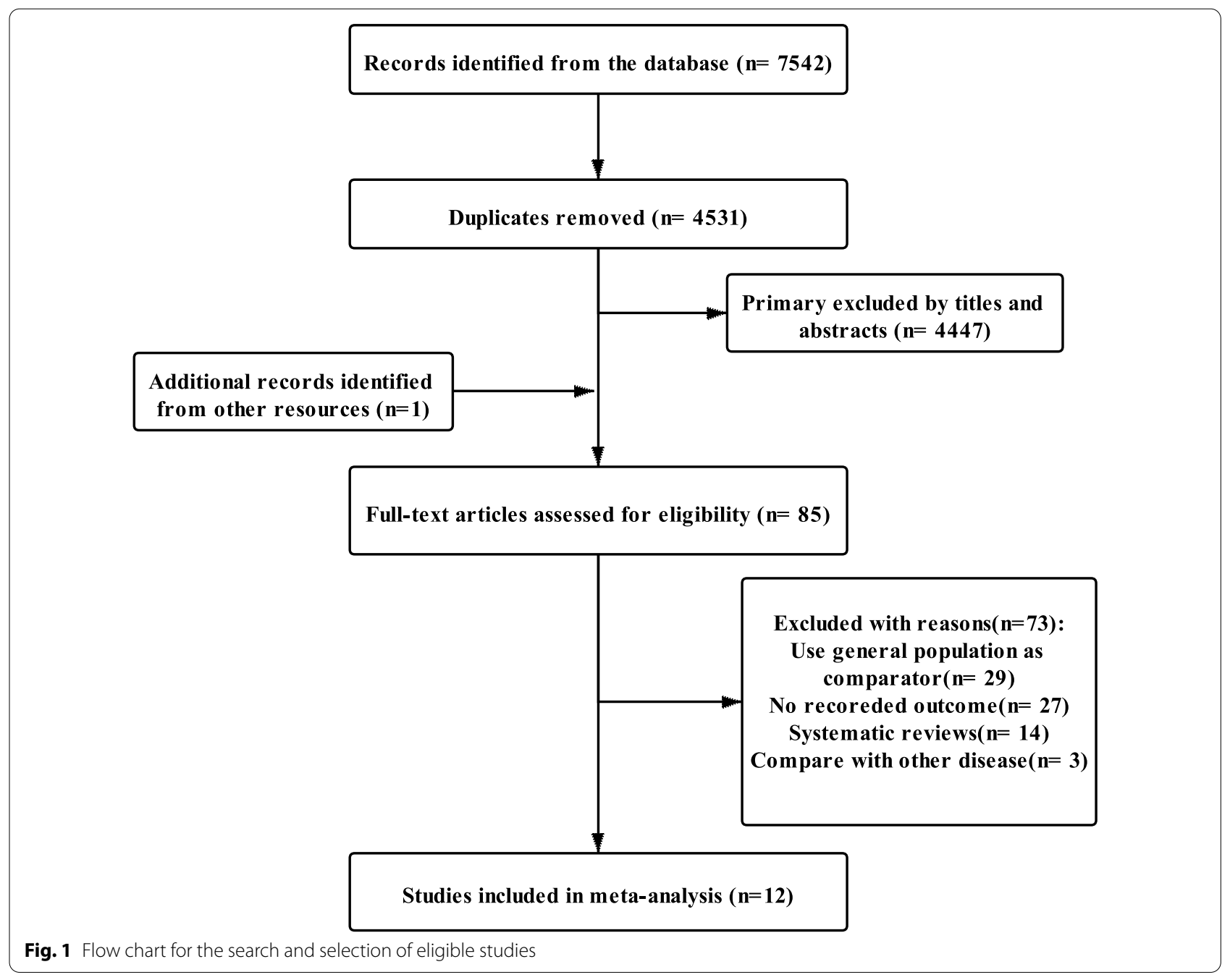


screening. The remaining 84 articles and one more paper discovered by hand-searching were read in their entirety and assessed for eligibility. Of these studies, three studies compared different diseases as control, 14 studies were systematic reviews, 27 studies did not report the outcome, and 29 studies used the general population as comparator group. Ultimately, we included 12 articles for analysis.

\section{Characteristics of included studies}

The 12 included studies were published from 2007 to 2019, and all were observational studies conducted in the USA $(n=8)$, Sweden $(n=2)$, the UK $(n=1)$, and Demark $(\mathrm{n}=1$; Table 1). Amongst these included studies, eight investigations were carried out on patients with RA [9, 34-40], one on patients with IBD [41], two on patients with psoriasis $[42,43]$, and one on patients with all these three diseases [44]. In all, 109,578 patients were treated with biologics, and 191,062 biologic-naïve patients did not receive biologics. The average duration of treatment varied from 0.3 years to 5.9 years, with research periods spanning 1995 to 2015 (Table 1). The majority of the included studies $(\mathrm{n}=11)$ involved individuals treated with TNFIs [9, 34-39, 41-44]. Amongst them, eight articles only involved TNFIs treatment $[9,34,36,37,39$, $41,43,44]$, and three articles reported the independent outcome of adalimumab, etanercept, and infliximab treatment $[34,39,43]$. In addition to TNFIs, individuals treated with rituximab (CD-20 inhibitor), abatacept (CD-28 inhibitor), and tocilizumab (IL-6 inhibitor) were also included in the research $[35,38,40]$. Age and gender adjustments were conducted in all the included studies. Furthermore, adjustment for prior or concurrent immunosuppressive therapy exposure was undertaken in one research [40], and adjustment for race/ethnicity (an indication of skin color, a key risk factor for NMSC) was carried out in four studies [9, 35, 42, 44]. However, UVR exposure was not adjusted in any of the included studies (Table 1).

\section{Quality assessment}

According to the NOS, three studies scored 7 and nine studies scored 8, meaning that all the included studies were assessed as high quality[30] (Additional file 1: Table S1). In the selection domain, all the included studies received the highest possible scores (4 of 4). In the comparability domain, all studies scored lout of 2 for the lack of adjustment for UVR exposure. There was no report on the number of people lost to follow-up or related information in studies from Dreyer, Wadström, and Kimball et al. [36, 38, 43].

\section{Risk of NMSC}

A random-effects model was used to calculate the summary RR of NMSC for patients treated with biologics versus those that did not receive biological drugs. The meta-analysis revealed that the use of biologics was linked with a greater risk of NMSC compared with no use of biologics in three common inflammatory diseases (RR 1.25, 95\% CI 1.14 to 1.37; Fig. 2). Amongst them, biological therapy also increased the risk of NMSC in patients with RA (RR 1.24, 95\% CI 1.13 to 1.36) and psoriasis (RR $1.28,95 \%$ CI 1.07 to 1.52 ), but not the risk of those with IBD (RR 1.49, 95\% CI 0.46 to 4.91). Heterogeneity was not significant in the RA $\left(\mathrm{I}^{2}=31.2 \%\right)$ and psoriasis $\left(\mathrm{I}^{2}=0.0 \%\right)$ subgroups. No publication bias was indicated in the included studies (Begg $P=0.99$; Egger $P=0.43$; Fig. 3).

\section{Subgroup analysis}

To analyze the consistency of results for connections between the usage of biologics and the risk of NMSC, as well as identifying potential causes of inter-study heterogeneity, we conducted subgroup analysis based on the types of NMSC, types of biological therapy, study quality, treatment years, and sample size in the models (Table 2). In the subgroup analysis by type of NMSC, biologics both raised the risk for patients with basal cell skin cancer (BCC; RR 1.16, 95\% CI 1.02 to 1.32) and squamous cell skin cancer (SCC; RR 1.34, 95\% CI 1.10 to 1.63; Additional file 2: Fig.S1a). However, subgroup analysis based on types of biologics demonstrated that both TNFIs (RR $1.23,95 \%$ CI 1.10 to 1.37 ) and abatacept (RR 2.00, 95\% CI 1.27 to 3.15) increased the risk of NMSC in patients with related inflammatory diseases, while rituximab (RR 1.02, 95\% CI 0.67 to 1.56 ) did not show the same trend (Additional file 2: Fig. S1b). Furthermore, treatment with biologics for more than 2 years increased the risk of NMSC compared with non-biological treatments (RR 1.26, 95\% CI 1.17 to 1.37), whereas no significant association was found for receiving biologics less than 2 years and the risk of NMSC (RR 1.04, 95\% CI 0.79 to 1.37; Additional file 2: Fig. S1c). Also, regardless of study quality or sample size, patients who used biologics had a higher incidence of NMSC than those who did not use biologics (Additional file 2: Fig. S1d and S1e).

\section{Discussion}

In the current meta-analysis, a significant association was identified between biological drug exposure and the development of NMSC in patients with three immune-mediated inflammatory diseases. Further analysis demonstrated that biologic-treated patients with RA and psoriasis, but not patients with IBD, had a higher 


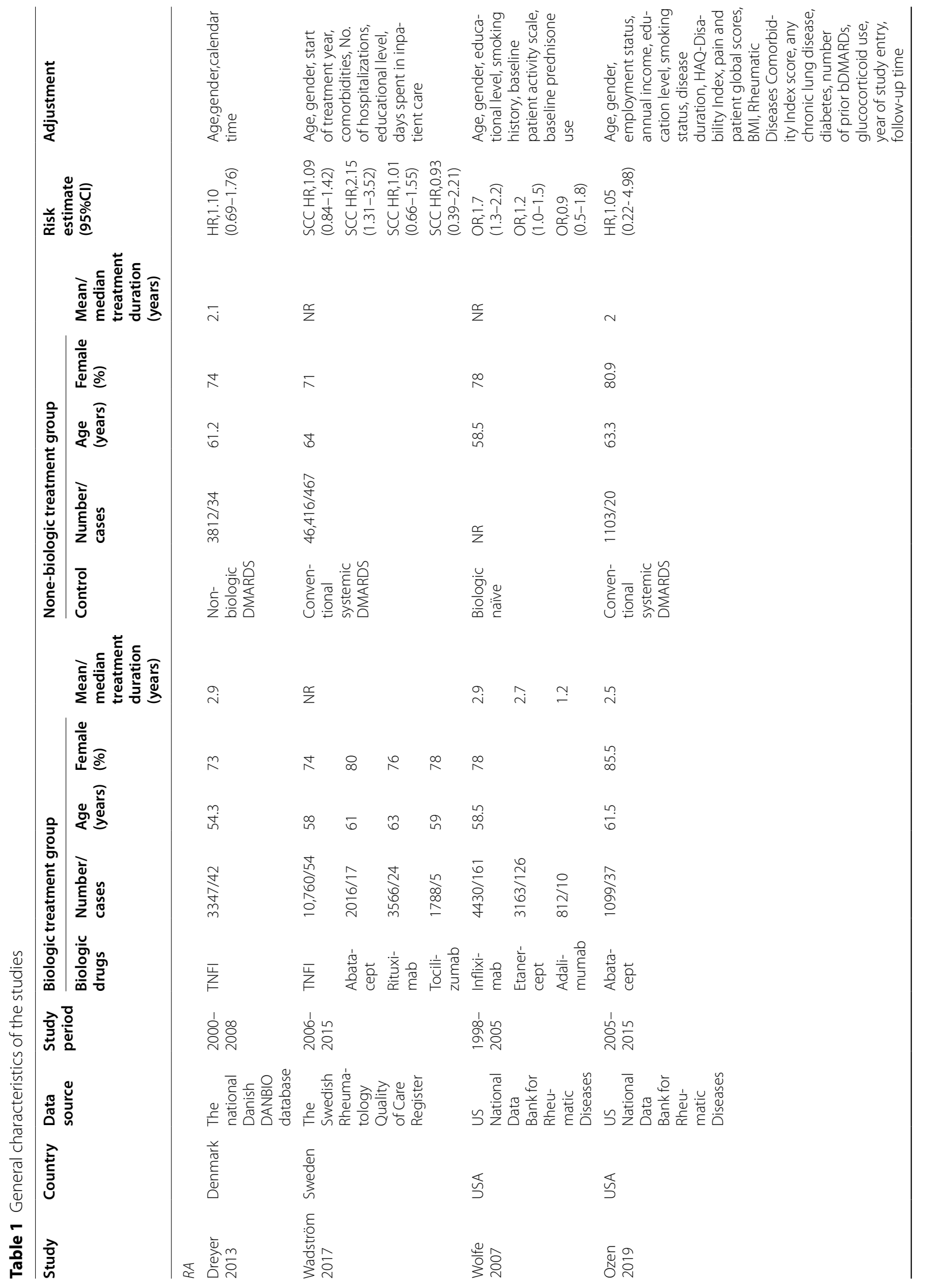




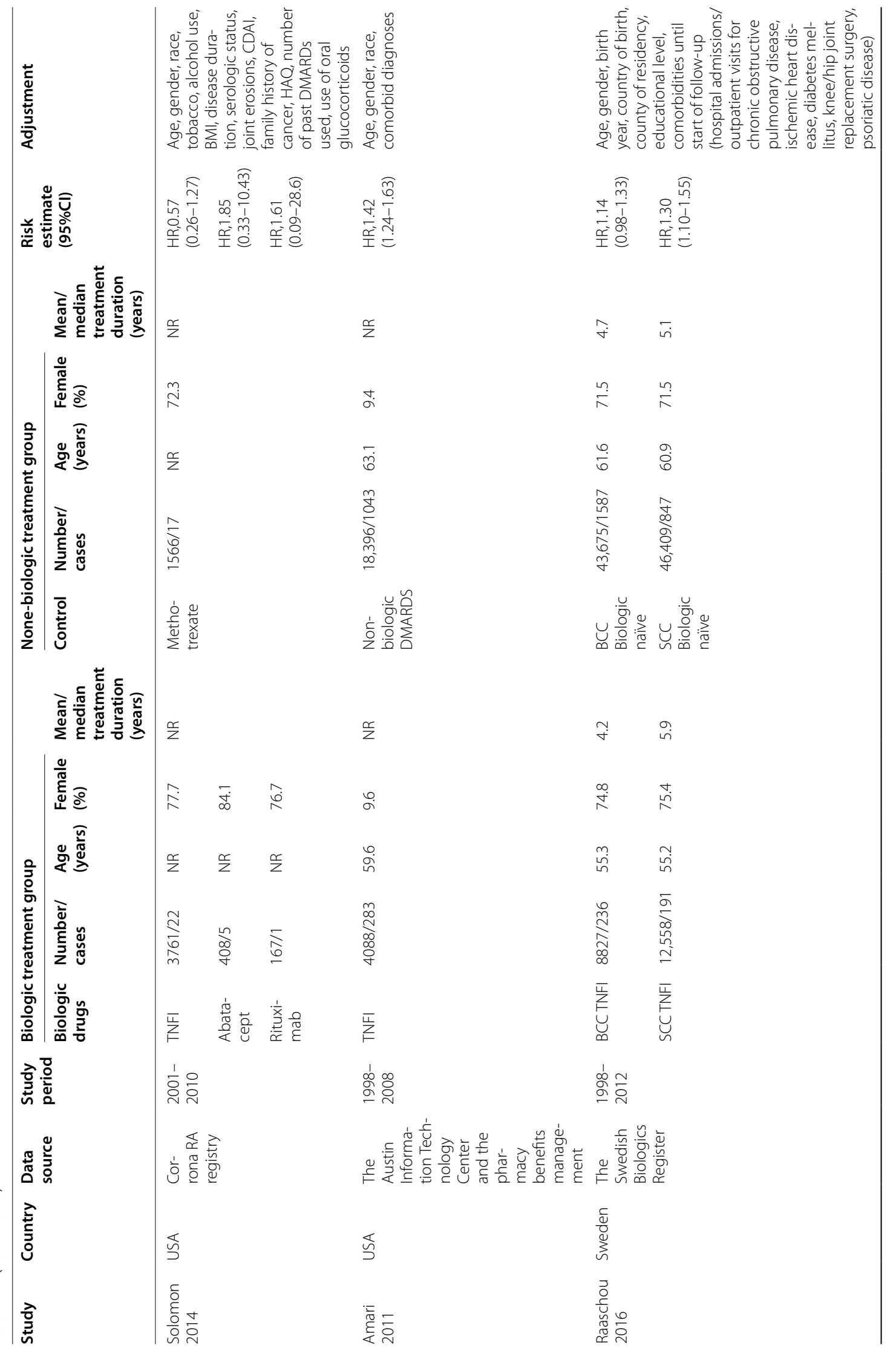




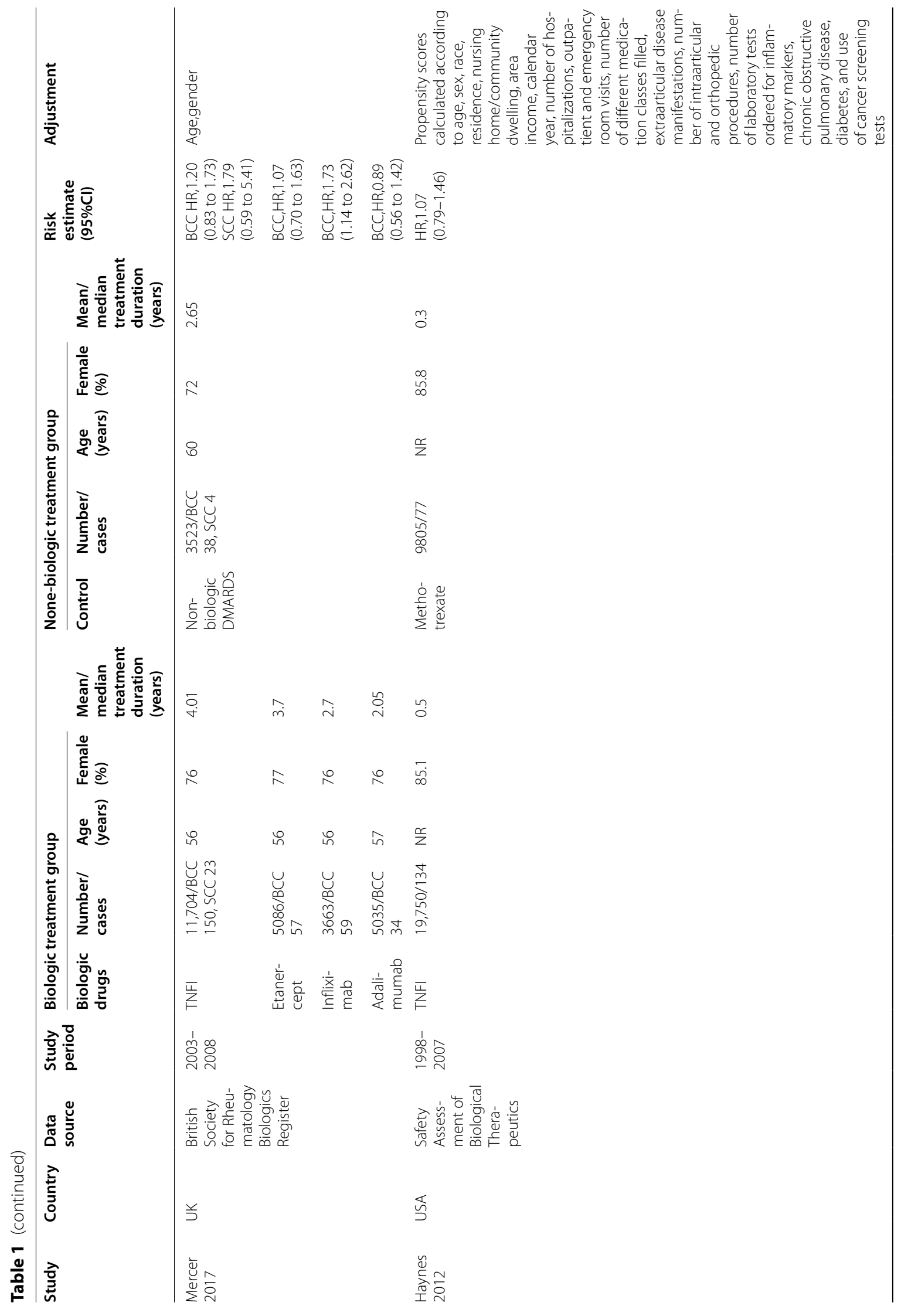




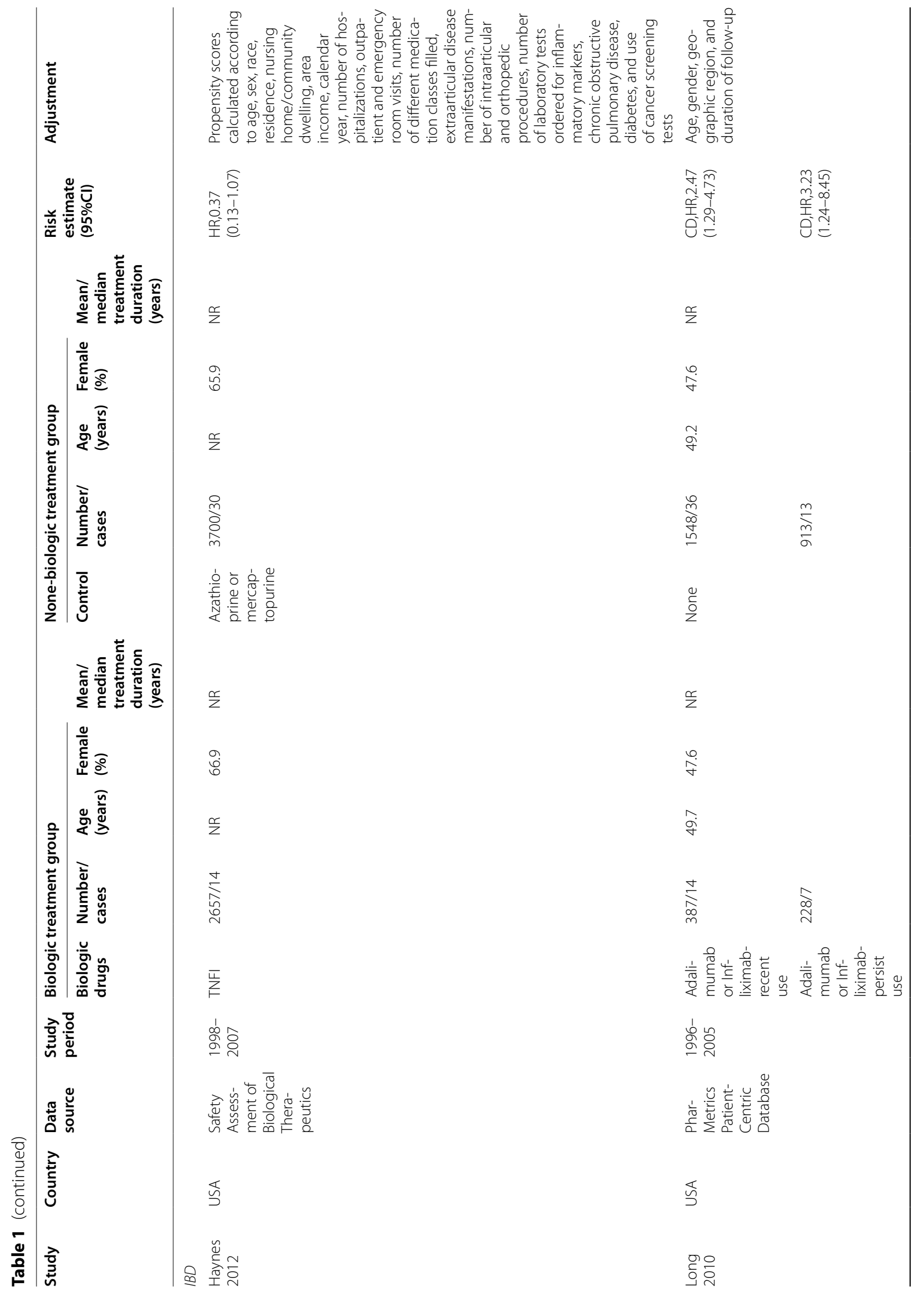




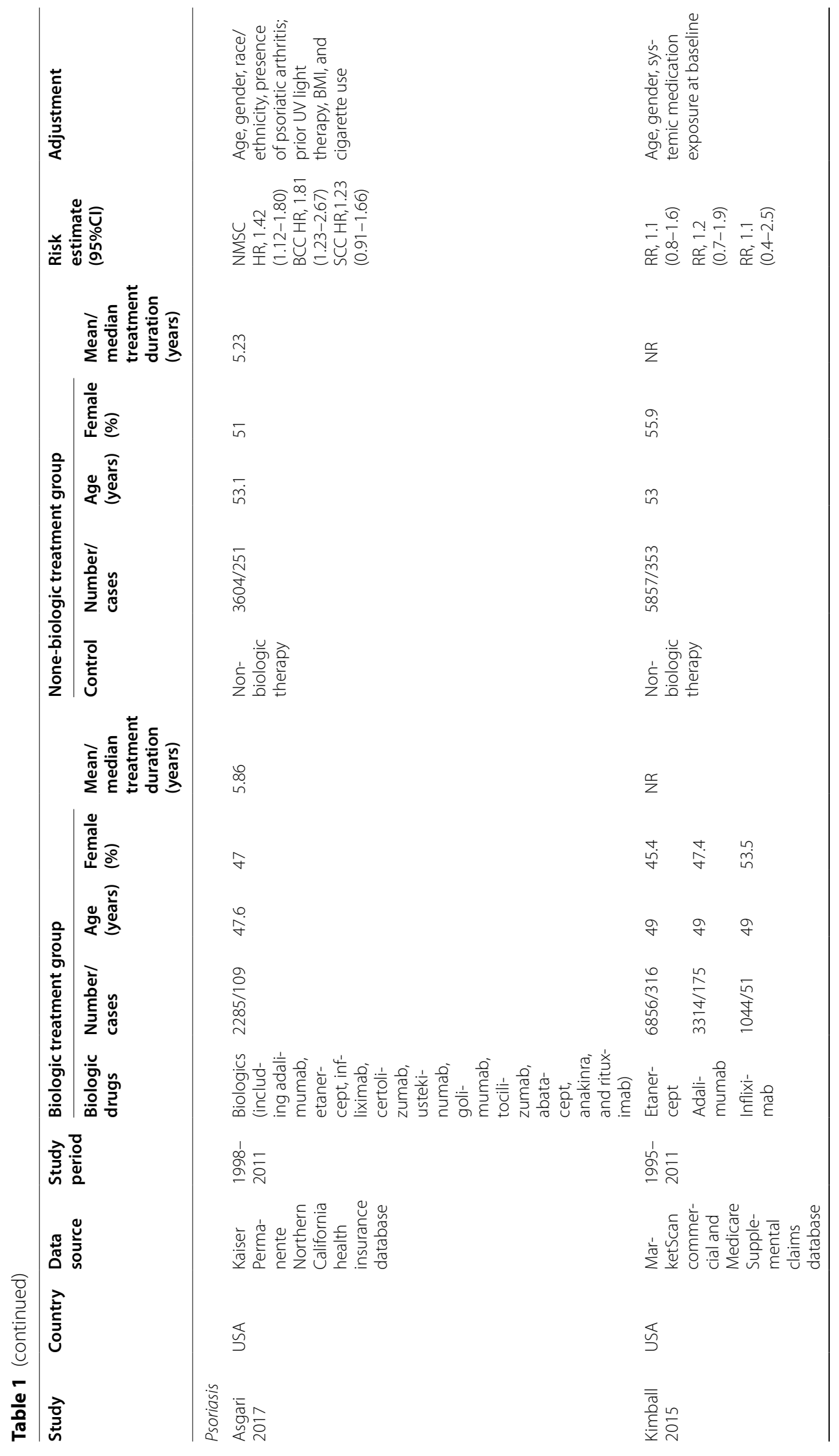




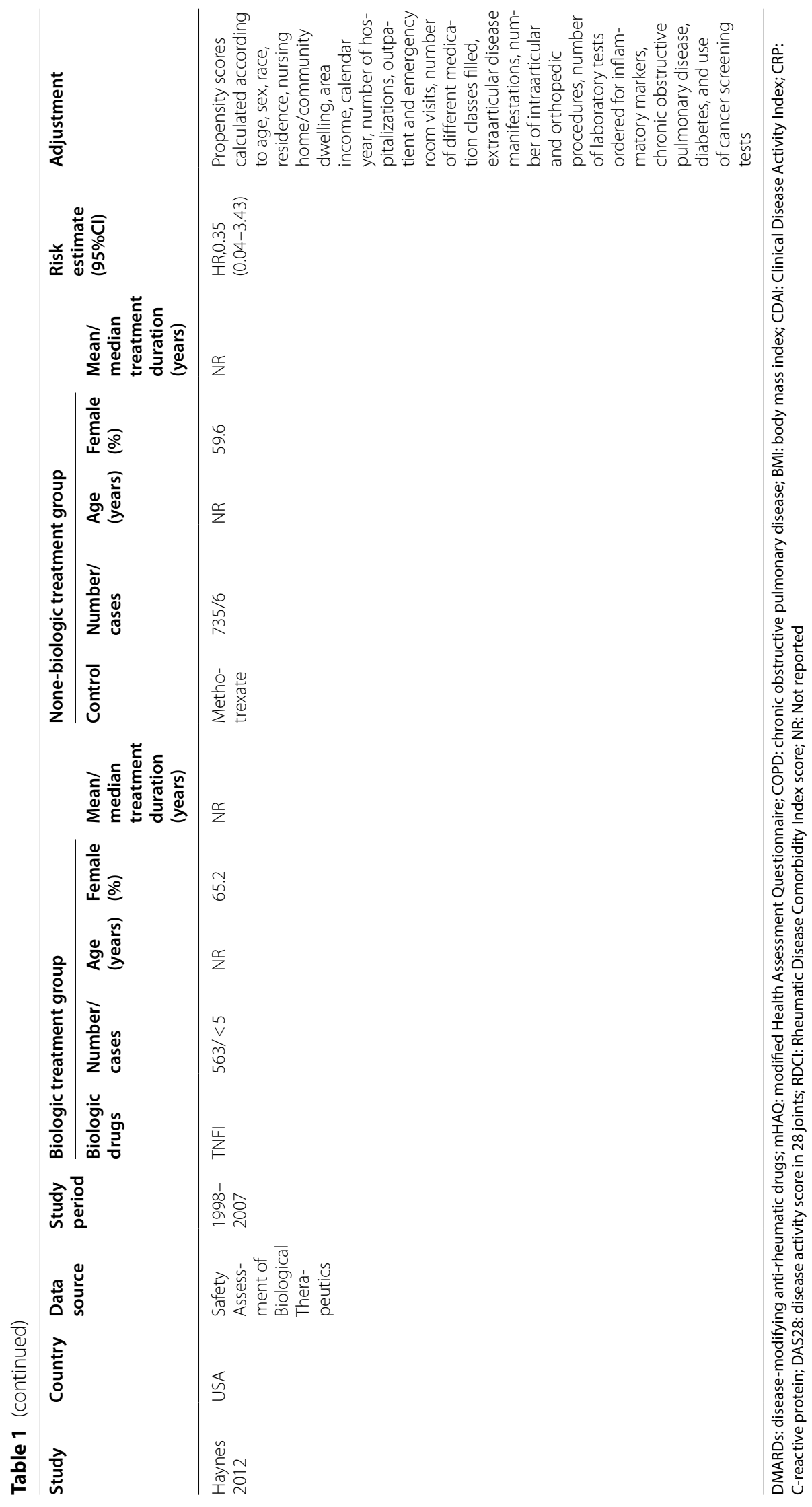


incidence of NMSC compared with patients treated with non-biological therapy. Based on previous studies, the most important alternate options for these patients could be their non-biological comparators, including methotrexate (MTX), hydroxychloroquine, sulfasalazine, or leflunomide for RA patients and MTX, cyclosporine, ciclosporin, hydroxyurea, mycophenolate mofetil, sulfasalazine, or thioguanine for psoriasis patients [42, 44]. These drugs should be considered for patients prone to NMSC, such as patients with red hair color or a family history of NMSC $[45,46]$. Recently, evidence has emerged that non-biological therapies are not inferior to biological treatments for RA patients, especially when administered early in the disease's course [47-50]. Furthermore, considering the high costs and risk of serious infections [51, 52], the use of biologics should be cautious.

To the best of our knowledge, this work is the first meta-analysis to explicitly investigate the risk of NMSC in patients with IBD and psoriasis who received biological therapy compared with their biologic-naïve patients. A meta-analysis of any cancer reported an increased risk of NMSC in patients with IBD without assessing the effect of any treatments [53]. At present, only one other pan-cancer systematic review involved the relationship between biologics-treated IBD patients and the risk of NMSC [19]. However, the comparator group included in this study was the general population and no meta-analysis was performed. The lack of a biologic-naïve comparison group for patients with IBD in two studies left unresolved problems of whether the observed results are due to the disease, the treatments, or both [54]. As we only included the studies that directly compared biologic-treated IBD patients with biologicnaive IBD patients, our study offers a more rigorous and clinically relevant estimate of the risk for NMSC in biologic-treated IBD patients. In this study, no significant association was found between IBD patients treated with biologics and the increased risk of NMSC; therefore, other key factors related to the increased risk of NMSC in IBD patients should be discussed, such as thiopurines treatment [55]. Considering the significant variation of the results between the only two included studies, more relevant original studies are needed in future studies to further clarify this issue [41, 44].

At present, the only systemic review of the pan-cancer study involving the risk of NMSC in patients with psoriasis also treated the general population as comparator group without estimating relevant effect, which demonstrated an increased risk of NMSC in patients with biologic-treated psoriasis compared with the general population [18]. In the current study, we included three studies that reported the NMSC risk on patients with biologic-treated psoriasis compared with the non-biologic-treated patients, which showed an increased risk of NMSC in the meta-analysis.

Previous meta-analyses have indicated a relationship between the risk of NMSC and biological treatment in RA patients, which yielded similar results to our study. Xie et al. summarized four studies and demonstrated that patients with biologic-treated RA had a higher risk of NMSC (RR 1.26, 95\% CI 1.09 to 1.45) compared with non-biologic treated individuals [21]. The data by Wang et al. indicated that TNFIs therapy in patients with RA is associated with increased risk of NMSC, but only associated with SCC and not associated with BCC [22]. In the current study, we indicated that biological therapy was also significantly related to the development of NMSC both in SCC and BCC.

BCC (about 70\%) and SCC (about 25\%) are the most prevalent kinds of NMSC [56]. Only two studies separately analyzing $\mathrm{BCC}$ and $\mathrm{SCC}$ were included in the previous meta-analysis, in which study population was limited to RA patients, and the study was limited to the association between TNFIs treatment and NMSC risk [22]. The current study extended the previous results by including more original studies assessing the risk of BCC and SCC separately. Thus, a more comprehensive analysis was conducted between the impact of biological therapy for three inflammatory diseases and the incidence of the two main subtypes of NMSC.

In subgroup analysis, biological therapy for more than 2 years was significantly associated with the increased risk of NMSC in three inflammatory diseases, while no significant association was found for less than 2 years' treatment and the increased risk of NMSC, indicating that the risk of NMSC was related to the duration of biological therapy. However, not all the included studies contained the information of mean treatment duration. For IBD patients, the data of mean treatment duration were missed, and 3 months was used as the minimal treatment duration [41], which suggested that numerous patients were treated with biologics for less than 2 years. For patients with biologic-treated RA and psoriasis, the longest mean treatment duration was up to 5.9 years and 5.86 years, respectively. Based on the information collected from the included studies, we infer that treatment duration might partially explain the difference in NMSC risk between the IBD patients' group and the other two groups.

To further clarify the impact of different biological treatments on the occurrence of NMSC, we conducted a subgroup analysis by different biological treatments. The results showed that TNFIs and abatacept were both associated with the increased risk of NMSC in inflammatory diseases. However, no significant difference was 


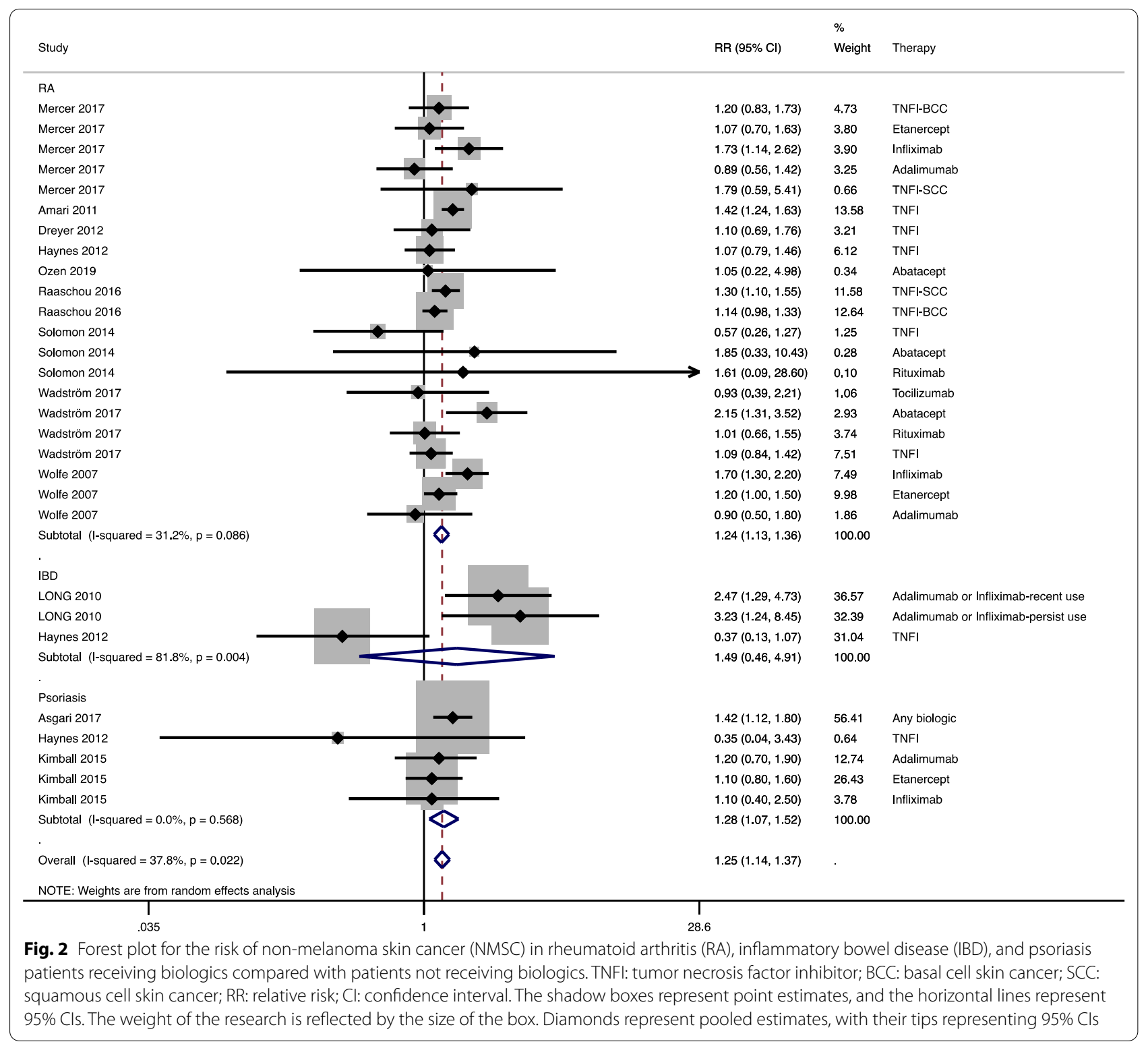

identified between the use of rituximab and the risk of NMSC in RA patients.

TNFIs were the most often used biologics in all the three common inflammatory diseases groups, as shown in Table 1. There are some biological reasons for the relationship between TNFIs therapy and the increased risk of NMSC. TNF is a key cytokine that modulates the inflammatory response and may play a role in tumor formation, which can regulate cell survival, proliferation, and cell death, as well as the transcription of proinflammatory cytokines by activating pathways [57]. TNF can either induce tumor cell death or survival depending on the conditions. The risk of developing NMSC from being treated with TNFIs has been widely studied in patients with RA. A previous meta-analysis based on six original articles also reported an increased risk of NMSC in patients with TNFI-treated RA [22]. In the subgroup analysis of TNFIs treatment, this meta-analysis included more relevant original studies, which increased the robustness and reliability of the results.

As a cytotoxic T-lymphocyte-associated protein 4-fusion protein, abatacept specifically inhibits $\mathrm{T}$ cell activation, which has been licensed to treat RA. Abatacept is likely related to an increased risk of cancer as it reduces anti-tumor response and immune surveillance $[58,59]$. In the included studies, only three studies involved abatacept, and all were based on RA populations $[35,38,40]$. One in three studies based on 2016 RA 


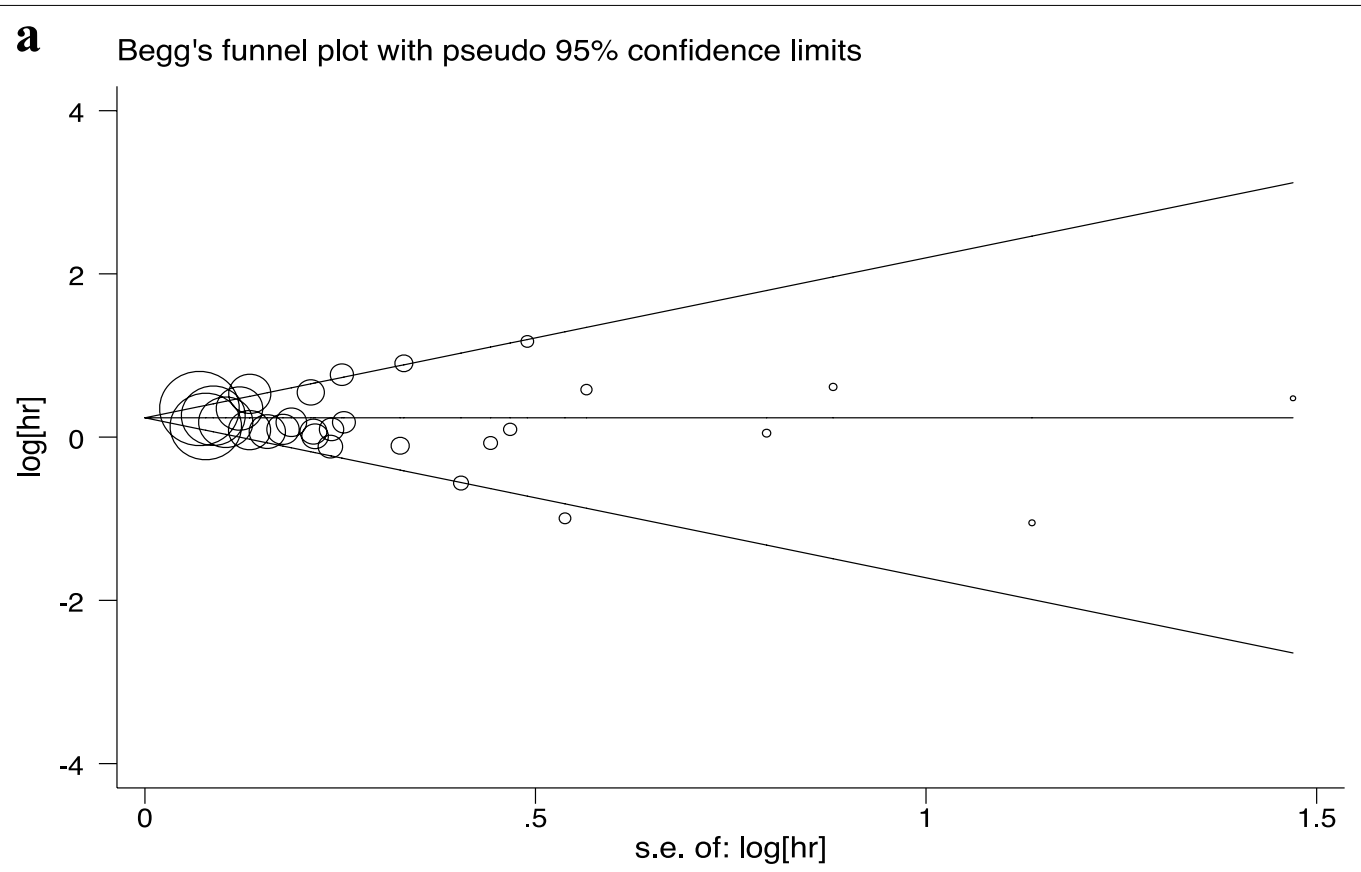

b Egger's publication bias plot

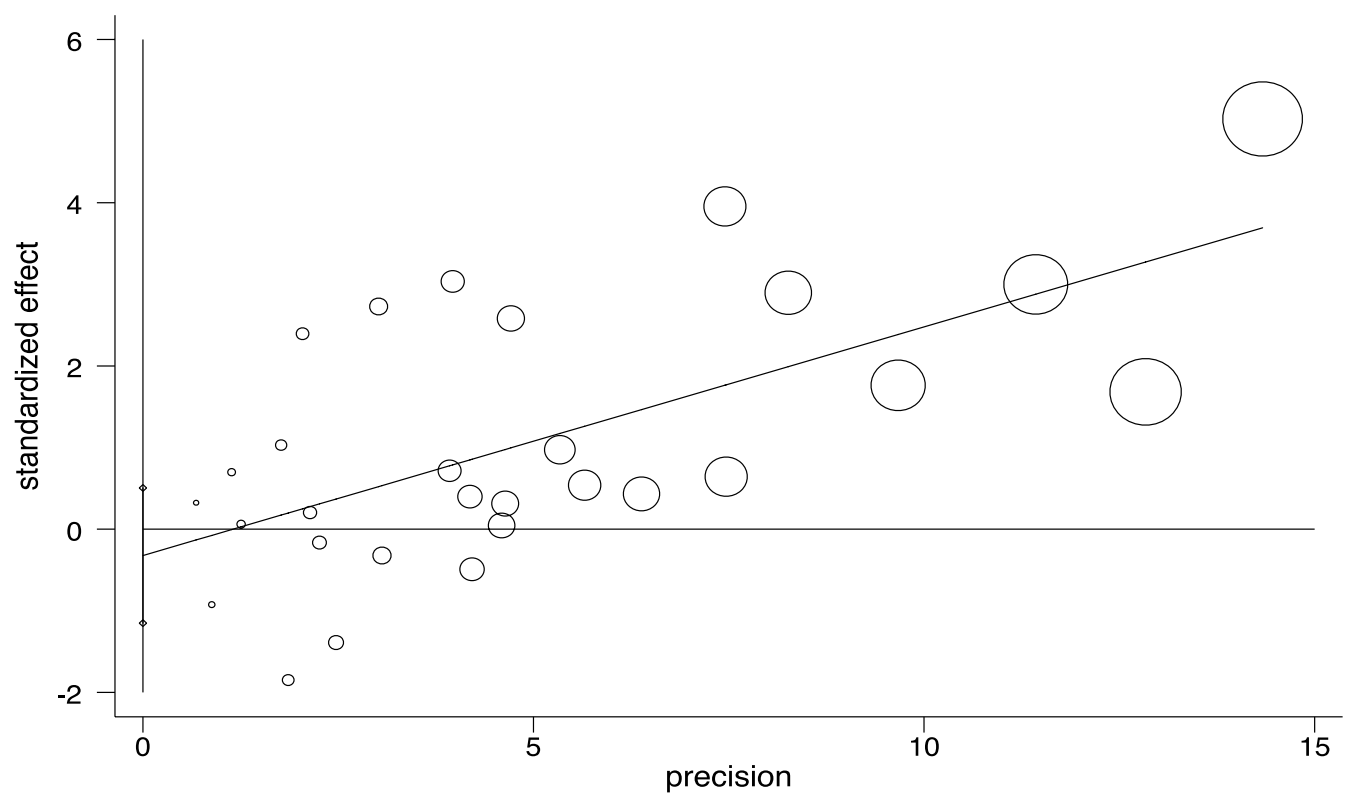

Fig. 3 Publication bias. a Begg's test $(P=0.99)$; b Egger's test $(P=0.43)$

patients found a significant association between the abatacept therapy and the risk of NMSC (RR 2.15, 95\% CI 1.31 to 3.52) [38]. Although the other two studies did not find a significant relationship between the use of abatacept and the risk of NMSC, their sample sizes were relatively small $[35,40]$. Rituximab has been extensively used in lymphoma patients and is now licensed for RA based on growing evidence of effectiveness and short-term safety [60]. However, little is known about the effects of rituximab exposure on the risk of NMSC. The study population of the two included studies involving rituximab only involved patients with RA, including the study published by Wadström et al. [38] in 2017 and the study published by Solomon et al. [35] in 2014. Neither study found 
Table 2 Association between biological therapy and risk of NMSC in subgroup meta-analyses

\begin{tabular}{|c|c|c|c|c|}
\hline Subgroup & No. of studies & $\operatorname{RR}(95 \% \mathrm{Cl})$ & $I^{2}$ value $(\%)$ & $P$ value \\
\hline All studies & 12 & $1.25(1.14,1.37)$ & 37.8 & 0.022 \\
\hline \multicolumn{5}{|l|}{ Type of NMSC } \\
\hline Squamous cell skin cancer & 4 & $1.34(1.10,1.63)$ & 44.2 & 0.096 \\
\hline Basal cell skin cancer & 3 & $1.16(1.02,1.32)$ & 0.0 & 0.893 \\
\hline \multicolumn{5}{|l|}{ Type of biologic therapy } \\
\hline TNFI & 10 & $1.23(1.10,1.37)$ & 45.2 & 0.017 \\
\hline Abatacept & 3 & $2.00(1.27,3.15)$ & 0.0 & 0.689 \\
\hline Rituximab & 2 & $1.02(0.67,1.56)$ & 0.0 & 0.754 \\
\hline \multicolumn{5}{|l|}{ Treatment years } \\
\hline Less than 2 years & 2 & $1.04(0.79,1.37)$ & 0.0 & 0.633 \\
\hline More than 2 years & 6 & $1.26(1.17,1.37)$ & 19.9 & 0.248 \\
\hline \multicolumn{5}{|l|}{ Study quality } \\
\hline NOS score $=7$ & 3 & $1.16(1.00,1.35)$ & 0.4 & 0.426 \\
\hline NOS score $=8$ & 9 & $1.29(1.15,1.44)$ & 42.8 & 0.028 \\
\hline \multicolumn{5}{|l|}{ Sample size } \\
\hline$<10,000$ & 12 & $1.26(1.12,1.42)$ & 45.0 & 0.009 \\
\hline$\geq 10,000$ & 4 & $1.21(1.07,1.36)$ & 0.0 & 0.667 \\
\hline
\end{tabular}

NMSC: non-melanoma skin cancer; TNFIs: tumor necrosis factor inhibitors; NOS: Newcastle-Ottawa Quality Assessment Scale; RR: relative risk; Cl: confidence interval

a significant relationship between rituximab therapy and the occurrence of NMSC. A previous study found no significant difference in the incidence of NMSC in kidney transplant recipients receiving rituximab treatment compared with the recipients not receiving rituximab treatment, which was consistent with the results of our study [61]. Based on the above results, more and larger studies are needed to analyze the longer safety of biological drugs, especially for abatacept and rituximab.

The severity of the disease could also be an important factor in analyzing the risk of NMSC [62]. Previous studies identified that the severity of RA is related to the risk of non-Hodgkin lymphoma, and the authors explain their findings in terms of increased cumulative inflammatory activity [63]. Moreover, the severity of IBD is associated with the development of colorectal cancer, which is considerably related to the extent of colitis $[64,65]$. However, to the best of our knowledge, the severity of the disease has not been considered as the risk factor for the development of NMSC in biologic-treated patients with common inflammatory diseases compared with the patients receiving non-biological treatments. Therefore, the subgroup analysis classified by the severity of the disease could not be conducted. Considering the effect of inflammatory disease severity in other types of cancer, the risk of NMSC might also be influenced. Thus, the severity of the common inflammatory disease should be considered while studying the risk of NMSC in biologic-treated patients in future research.
The following are the strengths of this meta-analysis. First, to decrease the possibility of missing reports, we thoroughly searched five major databases without publication dates or language constrains. Secondly, our analysis followed a predefined protocol to include studies that met rigorous inclusion and exclusion criteria. Thirdly, several stratified analyses were carried out based on several influential study variables, including types of NMSC, types of biological therapy, study quality, treatment years, and sample size. Fourth, all articles included in this study received a relatively high score according to the NOS.

Nevertheless, this meta-analysis had several limitations. The small number of IBD- and psoriasis-specific studies comparing the risk of NMSC between biologictreated non-biologic treated patients was the major limitation in this meta-analysis. Despite our thorough search, we only found two articles on IBD and three articles on psoriasis qualified for inclusion. Furthermore, the $\mathrm{I}^{2}$ value identified significant inter-study heterogeneity in the meta-analysis for IBD patients, which was understandable given the wide range of differences across studies regarding recruited participants, treatment drugs, and other study characteristics. Therefore, we conducted subgroup analysis for different research characteristics, partially explaining the heterogeneity among the studies. Also, more studies assessing the association of biological therapy and the incidence of NMSC in patients with IBD and psoriasis are needed.

Moreover, cohort studies have a more significant chance of irreversible bias, mainly confounding, than 
other types of work. Although all studies corrected for age and gender for NMSC risk, the possibility of bias from unmeasured confounders, which might result in overestimation or underestimating for effect estimate, also remained. For example, the absence of correction for known risk variables for NMSC, including UVR exposure and race/ethnicity, was observed in the studies included in this analysis.

Additionally, although no conclusive evidence of publication bias was found based on the Begg's and Egger's tests, as we did not search for unpublished articles or other such literature, we cannot entirely rule out the potential of publication bias. Finally, the estimates were based on 12 studies from Europe or the US, while data from other regions, such as Asia and Africa, were inaccessible. Therefore, we need to be cautious in generalizing the findings in this meta-analysis to other regions' populations.

\section{Conclusion}

This study found a positive association between biological therapy and the increased development of NMSC in patients with RA and psoriasis but not in patients with IBD compared with patients not receiving biological therapy. Therefore, biological therapy might be avoided in patients with RA or psoriasis who are at high risk of NMSC. The inner cause for the increased risk of NMSC in IBD patients should be further discussed. Considering the significant heterogeneity of IBD in previously published studies, we propose that further large, welldesigned studies on this issue are warranted to enhance assurance. The main risk factors for NMSC should also be taken into consideration in future studies.

\begin{abstract}
Abbreviations
BCC: Basal cell skin cancer; BMI: Body mass index; CDAl: Clinical Disease Activity Index; Cl: Confidence interval; DMARDs: Disease-modifying anti-rheumatic drugs; HAQ: Health Assessment Questionnaire; IBD: Inflammatory bowel disease; MOOSE: Meta-analysis of observational studies in Epidemiology guidelines; MTX: Methotrexate; NMSC: Non-melanoma skin cancer; NOS: Newcastle-Ottawa Quality Assessment Scale; PRISMA: Preferred Reporting Items for Systematic Reviews and Meta-Analyses guidelines; RA: Rheumatoid arthritis; RR: Relative risk; SCC: Squamous cell skin cancer; TNFI: Tumor necrosis factor inhibitor.
\end{abstract}

\section{Supplementary Information}

The online version contains supplementary material available at https://doi. org/10.1186/s12935-021-02325-9.

Additional file 1: Table S1. Methodological quality of studies included in the final analysis based on the Newcastle-Ottawa Scale.

Additional file 2: Fig. S1. Forest plot for the subgroup analysis of the risk for non-melanoma skin cancer (NMSC) in patients with common inflammatory diseases receiving biologics compared with patients not receiving biologics classified by (a) types of NMSC, (b) types of biological treatments, (c) treatment years, (d) Newcastle-Ottawa Quality Assessment
Scale (NOS) score, and (e) sample size. RA: rheumatoid arthritis; IBD: inflammatory bowel disease; TNFI: tumor necrosis factor inhibitor; BCC: basal cell skin cancer; SCC: squamous cell skin cancer; RR, relative risk; Cl, confidence interval. The shadow boxes represent point estimates, and the horizontal lines represent 95\% Cls. The weight of the research is reflected by the size of the box. Diamonds represent pooled estimates, with their tips representing $95 \% \mathrm{Cls}$

Additional file 3. Detailed search strategy.

\section{Acknowledgements}

Not applicable.

\section{Authors' contributions}

RLL: literature search, data collection, data analysis, and manuscript drafting. QYW: literature search and data collection. RZ: literature search and data analysis. HTX: critical revision. YC: study design and critical revision. XWX: study design, data analysis, and critical revision. All authors read and approved the final manuscript.

\section{Funding}

No funding was received for this work.

Availability of data and materials

All data generated or analyzed during this study are included in this article [and its supplementary information files].

\section{Declarations}

Ethics approval and consent to participate

Not applicable.

\section{Consent for publication}

Not applicable.

\section{Competing interests}

The authors declare that they have no competing interests.

\section{Author details}

${ }^{1}$ Department of Burn and Plastic Surgery, West China Hospital of Sichuan University, No 37 Wainan Guoxue Road, Chengdu 610041, China. ${ }^{2}$ Department of Gastrointestinal Surgery, West China Hospital of Sichuan University, Chengdu 610041, China.

Received: 19 July 2021 Accepted: 10 November 2021

Published online: 22 November 2021

\section{References}

1. Smolen JS, Aletaha D, McInnes IB. Rheumatoid arthritis. Lancet. 2016;388(10055):2023-38.

2. Kamm MA. Rapid changes in epidemiology of inflammatory bowel disease. Lancet. 2017:390(10114):2741-2.

3. Parisi R, Iskandar IYK, Kontopantelis E, Augustin M, Griffiths CEM, Ashcroft DM. National, regional, and worldwide epidemiology of psoriasis: systematic analysis and modelling study. Bmj. 2020;369:m1590.

4. David T, Ling SF, Barton A. Genetics of immune-mediated inflammatory diseases. Clin Exp Immunol. 2018;193(1):3-12.

5. Singh S, Nagpal SJ, Murad MH, Yadav S, Kane SV, Pardi DS, Talwalkar JA, Loftus EV Jr. Inflammatory bowel disease is associated with an increased risk of melanoma: a systematic review and meta-analysis. Clin Gastroenterol Hepatol. 2014;12(2):210-8.

6. Ishiyama K, Suwa A, Goto M, Hirakata M, Inoue K, Hara M, Inada S. Malignant melanoma in a patient with rheumatoid arthritis. Clin Exp Rheumatol. 1998;16(4):507.

7. Polesie S, Gillstedt M. Psoriasis and risk of cutaneous melanoma: a retrospective, comparative, registry-based cohort study. J Am Acad Dermatol. 2021. https://doi.org/10.1016/j.jaad.2021.01.084. 
8. Long MD, Martin CF, Pipkin CA, Herfarth HH, Sandler RS, Kappelman MD Risk of melanoma and nonmelanoma skin cancer among patients with inflammatory bowel disease. Gastroenterology. 2012;143(2):390-399. e391.

9. Amari W, Zeringue AL, McDonald JR, Caplan L, Eisen SA, Ranganathan P. Risk of non-melanoma skin cancer in a national cohort of veterans with rheumatoid arthritis. Rheumatology. 2011;50(8):1431-9.

10. Wang X, Liu Q, Wu L, Nie Z, Mei Z. Risk of non-melanoma skin cancer in patients with psoriasis: an updated evidence from systematic review with meta-analysis. J Cancer. 2020;11(5):1047-55.

11. Chatzikyriakidou A, Georgiou I, Voulgari PV, Drosos AA. The role of tumor necrosis factor (TNF)-alpha and TNF receptor polymorphisms in susceptibility to ankylosing spondylitis. Clin Exp Rheumatol. 2009;27(4):645-8.

12. Narazaki M, Tanaka T, Kishimoto T. The role and therapeutic targeting of IL-6 in rheumatoid arthritis. Expert Rev Clin Immunol. 2017;13(6):535-51.

13. Petitdemange A, Blaess J, Sibilia J, Felten R, Arnaud L. Shared development of targeted therapies among autoimmune and inflammatory diseases: a systematic repurposing analysis. Ther Adv Musculoskelet Dis. 2020. https://doi.org/10.1177/1759720X20969261.

14. Ruiz de Morales JMG, Puig L, Daudén E, Cañete JD, Pablos JL, Martín AO, Juanatey CG, Adán A, Montalbán X, Borruel N, et al. Critical role of interleukin (IL)-17 in inflammatory and immune disorders: an updated review of the evidence focusing in controversies. Autoimmun Rev. 2020;19(1):102429.

15. Naldi L. Biologic treatment for psoriasis and cancer: an increased risk for most cancers could not be ruled out. Br J Dermatol. 2018;178(1):19.

16. Esse S, Mason KJ, Green AC, Warren RB. Melanoma risk in patients treated with biologic therapy for common inflammatory diseases: a systematic review and meta-analysis. JAMA Dermatol. 2020;156(7):787-94.

17. van Lumig PP, Menting SP, van den Reek JM, Spuls PI, van Riel PL, van de Kerkhof PC, Fransen J, Kievit W, de Jong EM. An increased risk of non-melanoma skin cancer during TNF-inhibitor treatment in psoriasis patients compared to rheumatoid arthritis patients probably relates to disease-related factors. J Eur Acad Dermatol Venereol. 2015;29(4):752-60.

18. Peleva E, Exton LS, Kelley K, Kleyn CE, Mason KJ, Smith CH. Risk of cancer in patients with psoriasis on biological therapies: a systematic review. $\mathrm{Br} J$ Dermatol. 2018;178(1):103-13.

19. Muller M, D'Amico F, Bonovas S, Danese S, Peyrin-Biroulet L. TNF inhibitors and risk of malignancy in patients with inflammatory bowel diseases: a systematic review. J Crohns Colitis. 2021;15(5):840-59.

20. Singh A, Fatima K, Srivastava A, Khwaja S, Priya D, Singh A, Mahajan G, Alam S, Saxena AK, Mondhe DM, et al. Anticancer activity of gallic acid template-based benzylidene indanone derivative as microtubule destabilizer. Chem Biol Drug Des. 2016;88(5):625-34.

21. Xie W, Yang X, Huang H, Gao D, Ji L, Zhang Z. Risk of malignancy with non-TNFi biologic or tofacitinib therapy in rheumatoid arthritis: a metaanalysis of observational studies. Semin Arthr Rheum. 2020;50(5):930-7.

22. Wang JL, Yin WJ, Zhou LY, Zhou G, Liu K, Hu C, Zuo XC, Wang YF. Risk of non-melanoma skin cancer for rheumatoid arthritis patients receiving TNF antagonist: a systematic review and meta-analysis. Clin Rheumatol. 2020;39(3):769-78.

23. Sathish Kumar B, Kumar A, Singh J, Hasanain M, Singh A, Fatima K, Yadav DK, Shukla V, Luqman S, Khan F, et al. Synthesis of 2-alkoxy and 2-benzyloxy analogues of estradiol as anti-breast cancer agents through microtubule stabilization. Eur J Med Chem. 2014;86:740-51.

24. Srivastava A, Fatima K, Fatima E, Singh A, Singh A, Shukla A, Luqman S, Shanker K, Chanda D, Khan F, et al. Fluorinated benzylidene indanone exhibits antiproliferative activity through modulation of microtubule dynamics and antiangiogenic activity. Eur J Pharm Sci. 2020;154:105513.

25. Stroup DF, Berlin JA, Morton SC, Olkin I, Williamson GD, Rennie D, Moher D, Becker BJ, Sipe TA, Thacker SB. Meta-analysis of observational studies in epidemiology: a proposal for reporting. Meta-analysis Of Observational Studies in Epidemiology (MOOSE) group. Jama. 2000;283(15):2008-12.

26. Moher D, Liberati A, Tetzlaff J, Altman DG. Preferred reporting items for systematic reviews and meta-analyses: the PRISMA statement. PLoS Med. 2009:6(7):e1000097.

27. Hamid AA, Kaushal T, Ashraf R, Singh A, Chand Gupta A, Prakash O, Sarkar J, Chanda D, Bawankule DU, Khan F, et al. (22ß,25R)-3ß-Hydroxy-spirost5-en-7-iminoxy-heptanoic acid exhibits anti-prostate cancer activity through caspase pathway. Steroids. 2017;119:43-52.
28. Khwaja S, Fatima K, Hasanain M, Behera C, Kour A, Singh A, Luqman S, Sarkar J, Chanda D, Shanker K, et al. Antiproliferative efficacy of curcumin mimics through microtubule destabilization. Eur J Med Chem. 2018;151:51-61.

29. Sathish Kumar B, Singh A, Kumar A, Singh J, Hasanain M, Singh A, Masood N, Yadav DK, Konwar R, Mitra K, et al. Synthesis of neolignans as microtubule stabilisers. Bioorg Med Chem. 2014;22(4):1342-54.

30. Stang A. Critical evaluation of the Newcastle-Ottawa scale for the assessment of the quality of nonrandomized studies in meta-analyses. Eur J Epidemiol. 2010;25(9):603-5.

31. Hamid AA, Hasanain M, Singh A, Bhukya B, Omprakash J, Vasudev PG, Sarkar J, Chanda D, Khan F, Aiyelaagbe OO, et al. Synthesis of novel anticancer agents through opening of spiroacetal ring of diosgenin. Steroids. 2014;87:108-18.

32. Jain S, Singh A, Khare P, Chanda D, Mishra D, Shanker K, KarakT. Toxicity assessment of Bacopa monnieri L. grown in biochar amended extremely acidic coal mine spoils. Ecol Eng. 2017;108:211-9.

33. Singh A, Fatima K, Singh A, Behl A, Mintoo MJ, Hasanain M, Ashraf R, Luqman S, Shanker K, Mondhe DM, et al. Anticancer activity and toxicity profiles of 2-benzylidene indanone lead molecule. Eur J Pharm Sci. 2015;76:57-67.

34. Wolfe F, Michaud K. Biologic treatment of rheumatoid arthritis and the risk of malignancy: analyses from a large US observational study. Arthritis Rheum. 2007;56(9):2886-95.

35. Solomon DH, Kremer JM, Fisher M, Curtis JR, Furer V, Harrold LR, Hochberg MC, Reed G, Tsao P, Greenberg JD. Comparative cancer risk associated with methotrexate, other non-biologic and biologic disease-modifying anti-rheumatic drugs. Semin Arthr Rheum. 2014;43(4):489-97.

36. Dreyer L, Mellemkjaer L, Andersen AR, Bennett P, Poulsen UE, Juulsgaard Ellingsen T, Hansen TH, Jensen DV, Linde L, Lindegaard HM, et al. Incidences of overall and site specific cancers in TNFalpha inhibitor treated patients with rheumatoid arthritis and other arthritides - a follow-up study from the DANBIO Registry. Ann Rheum Dis. 2013;72(1):79-82.

37. Raaschou P, Simard JF, Asker Hagelberg C, Askling J, ARTIS Study Group. Rheumatoid arthritis, anti-tumour necrosis factor treatment, and risk of squamous cell and basal cell skin cancer: cohort study based on nationwide prospectively recorded data from Sweden. BMJ. 2016;352:i262.

38. Wadstrom H, Frisell T, Askling J, Anti-Rheumatic Therapy in Sweden (ARTIS) Study Group. Malignant neoplasms in patients with rheumatoid arthritis treated with tumor necrosis factor inhibitors, tocilizumab, abatacept, or rituximab in clinical practice: a nationwide cohort study from Sweden. JAMA Intern Med. 2017;177(11):1605-12.

39. Mercer LK, Green AC, Galloway JB, Davies R, Lunt M, Dixon WG, Watson KD, British Society for Rheumatology Biologics Register Control Centre Consortium, Symmons DP, Hyrich KL, et al. The influence of anti-TNF therapy upon incidence of keratinocyte skin cancer in patients with rheumatoid arthritis: longitudinal results from the British Society for Rheumatology Biologics Register. Ann Rheum Dis. 2012;71 (6):869-74.

40. Ozen G, Pedro S, Schumacher R, Simon TA, Michaud K. Safety of abatacept compared with other biologic and conventional synthetic diseasemodifying antirheumatic drugs in patients with rheumatoid arthritis: data from an observational study. Arthr Res Ther. 2019;21(1):141.

41. Long MD, Herfarth $H H$, Pipkin CA, Porter CQ, Sandler RS, Kappelman MD. Increased risk for non-melanoma skin cancer in patients with inflammatory bowel disease. Clin Gastroenterol Hepatol. 2010;8(3):268-74.

42. Asgari MM, Ray GT, Geier JL, Quesenberry CP. Malignancy rates in a large cohort of patients with systemically treated psoriasis in a managed care population. J Am Acad Dermatol. 2017;76(4):632-8.

43. Kimball AB, Schenfeld J, Accortt NA, Anthony MS, Rothman KJ, Pariser D. Cohort study of malignancies and hospitalized infectious events in treated and untreated patients with psoriasis and a general population in the United States. Br J Dermatol. 2015;173(5):1183-90.

44. Haynes K, Beukelman T, Curtis JR, Newcomb C, Herrinton LJ, Graham DJ, Solomon DH, Griffin MR, Chen L, Liu L, et al. Tumor necrosis factor alpha inhibitor therapy and cancer risk in chronic immune-mediated diseases. Arthr Rheum. 2013;65(1):48-58.

45. Jaju PD, Ransohoff KJ, Tang JY, Sarin KY. Familial skin cancer syndromes: Increased risk of nonmelanotic skin cancers and extracutaneous tumors. J Am Acad Dermatol. 2016;74(3):437-51 (quiz 452-434). 
46. Qureshi AA, Wei-Passanese EX, Li T, Han J. Host risk factors for the development of multiple non-melanoma skin cancers. J Eur Acad Dermatol Venereol. 2013;27(5):565-70.

47. Jacobs JWG. Lessons for the use of non-biologic anchor treatments for rheumatoid arthritis in the era of biologic therapies. Rheumatology. 2012;51(suppl_4):iv27-33.

48. Nam JL, Winthrop KL, van Vollenhoven RF, Pavelka K, Valesini G, Hensor EM, Worthy G, Landewé R, Smolen JS, Emery P, et al. Current evidence for the management of rheumatoid arthritis with biological diseasemodifying antirheumatic drugs: a systematic literature review informing the EULAR recommendations for the management of RA. Ann Rheum Dis. 2010;69(6):976-86.

49. Rau R. Efficacy of methotrexate in comparison to biologics in rheumatoid arthritis. Clin Exp Rheumatol. 2010;28(5 Suppl 61):S58-64.

50. Parida JR, Misra DP, Wakhlu A, Agarwal V. Is non-biological treatment of rheumatoid arthritis as good as biologics? World J Orthop. 2015;6(2):278-83.

51. Lluch P, Urruticoechea A, Lluch J, Moll MC, Matos M, Benet JM, Ene L, Cañete JD. Development of leprosy in a patient with rheumatoid arthritis during treatment with etanercept: a case report. Semin Arthr Rheum. 2012;42(2):127-30.

52. Chiu YM, Chen DY. Infection risk in patients undergoing treatment for inflammatory arthritis: non-biologics versus biologics. Expert Rev Clin Immunol. 2020;16(2):207-28.

53. Lo B, Zhao M, Vind I, Burisch J. The risk of extraintestinal cancer in inflammatory bowel disease: a systematic review and meta-analysis of population-based cohort studies. Clin Gastroenterol Hepatol. 2021;19(6):1117-38.

54. Singh A, Mohanty I, Singh J, Rattan S. BDNF augments rat internal anal sphincter smooth muscle tone via RhoA/ROCK signaling and nonadrenergic noncholinergic relaxation via increased NO release. Am J Physiol Gastrointest Liver Physiol. 2020;318(1):G23-33.

55. Solitano V, D'Amico F, Correale C, Peyrin-Biroulet L, Danese S. Thiopurines and non-melanoma skin cancer: partners in crime in inflammatory bowe diseases. Br Med Bull. 2020;136(1):107-17.
56. Leiter U, Eigentler T, Garbe C. Epidemiology of skin cancer. Adv Exp Med Biol. 2014;810:120-40.

57. Waters JP, Pober JS, Bradley JR. Tumour necrosis factor in infectious disease. J Pathol. 2013;230(2):132-47.

58. Korhonen R, Moilanen E. Abatacept, a novel CD80/86-CD28 T cell costimulation modulator, in the treatment of rheumatoid arthritis. Basic Clin Pharmacol Toxicol. 2009:104(4):276-84.

59. Blair HA, Deeks ED. Abatacept: a review in rheumatoid arthritis. Drugs. 2017:77(11):1221-33.

60. Tavakolpour S, Alesaeidi S, Darvishi M, GhasemiAdl M, Darabi-Monadi S, Akhlaghdoust M, Elikaei Behjati S, Jafarieh A. A comprehensive review of rituximab therapy in rheumatoid arthritis patients. Clin Rheumatol. 2019;38(11):2977-94.

61. Bachelet T, Visentin J, Davis P, Taton B, Guidicelli G, Kaminski H, Merville P, Couzi L. The incidence of post-transplant malignancies in kidney transplant recipients treated with Rituximab. Clin Transpl. 2021;35(2):e14171.

62. Singh A, Singh J, Rattan S. Evidence for the presence and release of BDNF in the neuronal and non-neuronal structures of the internal anal sphincter. Neurogastroenterol Motil. 2021. https://doi.org/10.1111/nmo.14099.

63. Calip GS, Patel PR, Adimadhyam S, Xing S, Wu Z, Sweiss K, Schumock GT, Lee TA, Chiu BCH. Tumor necrosis factor-alpha inhibitors and risk of nonHodgkin lymphoma in a cohort of adults with rheumatologic conditions. Int J Cancer. 2018;143(5):1062-71.

64. Nebbia M, Yassin NA, Spinelli A. Colorectal cancer in inflammatory Bowel disease. Clin Colon Rectal Surg. 2020;33(5):305-17.

65. Söderlund S, Brandt L, Lapidus A, Karlén P, Broström O, Löfberg R, Ekbom A, Askling J. Decreasing time-trends of colorectal cancer in a large cohort of patients with inflammatory bowel disease. Gastroenterology. 2009;136(5):1561-7 (quiz 1818-1569).

\section{Publisher's Note}

Springer Nature remains neutral with regard to jurisdictional claims in published maps and institutional affiliations.
Ready to submit your research? Choose BMC and benefit from:

- fast, convenient online submission

- thorough peer review by experienced researchers in your field

- rapid publication on acceptance

- support for research data, including large and complex data types

- gold Open Access which fosters wider collaboration and increased citations

- maximum visibility for your research: over $100 \mathrm{M}$ website views per year

At $\mathrm{BMC}$, research is always in progress.

Learn more biomedcentral.com/submissions 